Check for updates

Cite this: Chem. Sci., 2019, 10, 3807

๑ All publication charges for this article have been paid for by the Royal Society of Chemistry

Received 26th November 2018 Accepted 20th February 2019

DOI: $10.1039 / c 8 s c 05256 e$

rsc.li/chemical-science

\section{Discrimination between two memory channels by molecular alloying in a doubly bistable spin crossover material $\dagger$}

\author{
Francisco Javier Valverde-Muñoz, ${ }^{a}$ Maksym Seredyuk, (iD *ab Manuel Meneses- \\ Sánchez, ${ }^{a}$ M. Carmen Muñoz, (D) C Carlos Bartual-Murgui ${ }^{a}$ and José A. Real (iD *a
}

A multistable spin crossover (SCO) molecular alloy system $\left[\mathrm{Fe}_{1-x} \mathrm{M}_{x}(n \mathrm{Bu} \text {-im) })_{3}(\right.$ tren) $)\left(\mathrm{P}_{1-y} \mathrm{As}_{y} \mathrm{~F}_{6}\right)_{2}\left(\mathrm{M}=\mathrm{Zn}^{\prime \prime}\right.$, $\mathrm{Ni}^{\mathrm{Il}} ; \quad(\mathrm{nBu} \text {-im) })_{3}($ tren $)=$ tris( $n$-butyl-imidazol(2-ethylamino))amine) has been synthesized and characterized. By controlling the composition of this isomorphous series, two cooperative thermally induced SCO events featuring distinct critical temperatures $\left(T_{c}\right)$ and hysteresis widths $\left(\Delta T_{c}\right.$, memory) can be selected at will. The pristine derivative 100As $(x=0, y=1)$ displays a strong cooperative two-step SCO and two reversible structural phase transitions (PTs). The low temperature $\mathrm{PT}^{\mathrm{LT}}$ and the SCO occur synchronously involving conformational changes of the ligand's $n$-butyl arms and two different arrangements of the $\mathrm{AsF}_{6}{ }^{-}$anions $\left[T_{\mathrm{c}}^{1}=174 \mathrm{~K}\left(\Delta T_{\mathrm{c}}^{1}=17 \mathrm{~K}\right), T_{\mathrm{c}}^{2}=191 \mathrm{~K}\left(\Delta T_{\mathrm{c}}^{2}=23 \mathrm{~K}\right)\right.$ (scan rate $\left.2 \mathrm{~K} \mathrm{~min}^{-1}\right)$ ]. The high-temperature $\mathrm{PT}^{\mathrm{HT}}$ takes place in the high-spin state domain and essentially involves rearrangement of the $\mathrm{AsF}_{6}{ }^{-}$anions $\left[T_{\mathrm{c}}^{P \mathrm{P}}=275 \mathrm{~K}\left(\Delta T_{\mathrm{c}}^{\mathrm{PT}}=16 \mathrm{~K}\right)\right]$. This behavior strongly contrasts with that of the homologous 100P $[x=0, y=0]$ derivative where two separate cooperative one-step SCO can be selected by controlling the kinetics of the coupled $\mathrm{PT}^{\mathrm{LT}}$ at ambient pressure: (i) one at low temperatures, $T_{\mathrm{C}}=122 \mathrm{~K}\left(\Delta T_{\mathrm{c}}=9 \mathrm{~K}\right)$, for temperature scan rates $\left(>1 \mathrm{~K} \mathrm{~min}^{-1}\right)$ (memory channel $\left.\mathrm{A}\right)$ where the structural modifications associated with $\mathrm{PT}^{\mathrm{LS}}$ are inhibited; (ii) the other centered at $T_{\mathrm{C}}=155 \mathrm{~K}$ $\left(\Delta T_{\mathrm{c}}=41 \mathrm{~K}\right)$ for slower temperature scan rates $\leq 0.1 \mathrm{~K} \mathrm{~min}^{-1}$ (memory channel B). These two SCO regimes of the 100P derivative transform reversibly into the two-step SCO of 100As upon application of hydrostatic pressure (ca. $0.1 \mathrm{GPa}$ ) denoting the subtle effect of internal chemical pressure on the SCO behavior. Precise control of $\mathrm{AsF}_{6}{ }^{-} \leftrightarrow \mathrm{PF}_{6}{ }^{-}$substitution, and hence of the $\mathrm{PT}^{\mathrm{LT}}$ kinetics, selectively selects the memory channel $\mathrm{B}$ of $100 \mathrm{P}$ when $x=0$ and $y \approx 0.7$. Meanwhile, substitution of Fe" with $\mathrm{Zn}^{\prime \prime}$ or $\mathrm{Ni}^{\prime \prime}[x \approx 0.2, y=0]$ favors the low temperature memory channel $\mathrm{A}$ at any scan rate. This intriguing interplay between PT, SCO and isomorphous substitution was monitored by single crystal and powder Xray diffractometries, and magnetic and calorimetric measurements.

\section{Introduction}

Responsive switchable materials attract great attention due to affording excellent study examples for understanding the mechanisms of phase transitions (PTs) and provide application prospects for future and emerging technologies. ${ }^{1}$ Some of the most investigated switchable molecular materials are pseudooctahedral $\mathrm{Fe}^{\mathrm{II}}$ spin-crossover (SCO) complexes, reversibly

\footnotetext{
${ }^{a}$ Departament de Química Inorgànica, Institut de Ciència Molecular (ICMol), Universitat de València, Valencia, Spain.E-mail: jose.a.real@uv.es

${ }^{b}$ On leave from Department of Chemistry, Taras Shevchenko National University of Kyiv, 64/13, Volodymyrska Street, 01601, Kyiv, Ukraine. E-mail: mcs@univ.kiev.ua; mlseredyuk@gmail.com

${ }^{c}$ Departament de Física Aplicada, Universitat Politècnica de València, Camino de Vera $s / n$, E-46022, Valencia, Spain

$\dagger$ Electronic supplementary information (ESI) available. CCDC 1879896-1879901 and 1892385. For ESI and crystallographic data in CIF or other electronic format see DOI: $10.1039 / \mathrm{c} 8 \operatorname{sc} 05256 \mathrm{e}$
}

altering the high-spin (HS, $\left.\mathrm{t}_{2 \mathrm{~g}}^{4} \mathrm{e}_{\mathrm{g}}^{2}\right)$ and low-spin (LS, $\left.t_{2 g}^{6} e_{g}^{0}\right)$ electronic states by the action of physicochemical stimuli (temperature, pressure, light and chemical substrates). The LSHS conversion involves an electron transfer between the $\mathrm{e}_{\mathrm{g}}$ and $t_{2 g}$ orbitals strongly coupled with structural changes in the coordination core of the $\mathrm{Fe}^{\mathrm{II}}$ centres, which essentially affect Fe-ligand bond lengths and angles, and in turn the molecular conformation. In favourable cases these changes propagate cooperatively in the crystal, conferring bistability (memory) to the magnetic, optical, dielectric, structural and mechanical properties. $^{2}$

New developments in this area are crucial not only for elucidating background mechanisms behind observed properties and understanding the fundamental aspects of the SCO behaviour, but also for opening new perspectives in the field, such as the use of SCO compounds for creation of fully controllable "smart" materials responding to external stimuli in a desired way. ${ }^{3}$ For example, SCO can be combined with other relevant functions 
such as fluorescence, ${ }^{3 c, 4}$ electroluminescence, ${ }^{3 e}$ electronic transport $^{5}$ and non-linear optical response ${ }^{6}$ thereby transferring its intrinsic bistable nature to the second property resulting in multifunctional materials that can be processed at different levels, from bulk to nanoscale. ${ }^{7}$

The control of the SCO characteristics, i.e. critical temperature and hysteresis width, remains one of the key focuses in the field. Tackling this problem by chemical methods requires engineering both the coordination site of the SCO centres and the cohesive elastic interactions between them through supramolecular and/or polymeric approaches. Furthermore, the strong sensitivity of the SCO behaviour to subtle changes in the elastic interactions makes it possible to control the SCO through crystal lattice rearrangements. In this respect, isomorphous substitution of SCO metal centres/complexes with non-SCO metal ions ${ }^{8} /$ non-SCO complexes $^{9}$ is an effective means to modulate the SCO behaviour. For example, substantial dilution with passive $\mathrm{Ni}^{\mathrm{II}}$ or $\mathrm{Zn}^{\mathrm{II}}$-based complexes breaks cooperativity between SCO centres and brings on a considerable downward shift of the SCO equilibrium/critical temperature $T_{1}$ / ${ }_{2} / T_{\mathrm{c}}$, while low concentrations of the dopant can fine tune the SCO behavior. ${ }^{2 d}$ Metal dilution is a particular case of a more general concept of a solid solution of molecules, also known as molecular alloys, consisting in precise control of the stoichiometry of mixed ionic or molecular components during the synthetic step. This offers an unrivalled tool for optimization of desired magnetic, optical or electrical properties, as demonstrated by examples from adjacent fields, ${ }^{\mathbf{1 0}}$ and for a few SCO systems. ${ }^{3 a}$ Another relevant strategy, yet little explored, is based on the possibility of controlling the SCO properties by a PT. ${ }^{\mathbf{1 1}}$ It has been demonstrated for several systems that changes in the interaction binding between the components of the crystal due to a solid-solid or solid-liquid/liquid crystal PT may be sufficient for altering the spin state. ${ }^{\mathbf{1 1 b}, \mathbf{1 2}}$

In this context, the complex $\left[\mathrm{Fe}(n \mathrm{Bu}-\mathrm{im})_{3}(\right.$ tren $\left.)\right]\left(\mathrm{PF}_{6}\right)_{2}((n \mathrm{Bu}-$ $\mathrm{im})_{3}($ tren $)=\operatorname{tris}(n$-butyl-imidazol(2-ethylamino $)$ )amine $)$ affords an uncommon example of thermal hysteretic SCO behaviour deeply influenced by a synchronous symmetric crystallographic $\mathrm{PT}$, leading to a reorganization of the crystal lattice due to significant conformational changes of the alkyl groups and displacement and rotation of the $\mathrm{PF}_{6}{ }^{-}$anions, taking place during the LS $\leftrightarrow$ HS conversion. ${ }^{11 b}$ Playing with the slow kinetics featuring this PT, two well separate hysteretic thermally induced SCO behaviors (two memory channels) were found. ${ }^{11 b}$ Thus, high-temperature sweep rates $\left(\geq 2 \mathrm{~K} \mathrm{~min}^{-1}\right)$ quench the crystallographic PT thereby stabilizing channel A, which is characterized by a cooperative SCO, between the phases $\mathrm{HS}^{\mathbf{1}}$ and $\mathrm{LS}^{1}$, centred at $122 \mathrm{~K}$ with a hysteresis $14 \mathrm{~K}$ wide. In contrast, low temperature-sweep rates $\left(\leq 0.1 \mathrm{~K} \mathrm{~min}^{-1}\right)$ stabilize channel $\mathrm{B}$, characterized by a much more cooperative SCO, between the $\mathrm{HS}^{1}$ and $\mathrm{LS}^{2}$ phases, centred at $c a .155 .5 \mathrm{~K}$ featuring a hysteresis loop $41 \mathrm{~K}$ wide (see Scheme 1 ). The phases display different arrangement 1 and arrangement 2 of the flexible butyl groups and of the anions. Furthermore, the $\mathrm{LS}^{1}$ phase affords an uncommon very long-lived photogenerated $\mathrm{HS}^{1 *}$ phase after light irradiation at $80 \mathrm{~K}$. The very slow relaxation kinetics is controlled by conformational rearrangements of the butyl groups during the $\mathrm{HS}^{1 *} \rightarrow \mathrm{LS}^{1}$ transformation. ${ }^{11 f}$

In order to understand more in depth the correlation between SCO and structural PTs in 100P and find reliable chemical means to discriminate between the two thermal memory channels, we have investigated the isostructural compound $\left[\mathrm{Fe}(n \mathrm{Bu}-\mathrm{im})_{3}(\right.$ tren $\left.)\right]\left(\mathrm{AsF}_{6}\right)_{2} \quad(100 \mathrm{As})$ and the solid solutions $\left[\mathrm{Fe}_{1-x} \mathrm{M}_{x}(n \mathrm{Bu}-\mathrm{im})_{3}(\operatorname{tren})\right]\left(\mathrm{P}_{1-y} \mathrm{As}_{y} \mathrm{~F}_{6}\right)_{2}$ (see Scheme 1). Herein, we show that the SCO behavior of 100P $(x=0 ; y=0)$ is highly sensitive to application of external hydrostatic low pressure and, consequently, the resulting SCO behavior is similar to that of $100 \mathrm{As}(x=0 ; y=1)$ which also displays double bistability due to SCO and PTs but at higher temperatures. Furthermore, modulating the internal "chemical pressure" built up by partial substitution of $\mathrm{Fe}^{\mathrm{II}}$ with $\mathrm{M}^{\mathrm{II}}(x \mathrm{M}, x<100$ and $y$ $=0, \mathrm{M}=\mathrm{Zn}, \mathrm{Ni}$ ) or $\mathrm{P}$ with As ( $y \mathrm{As}, x=0$ and $y<100$ ) leads to effective discrimination of the two memory channels resulting from the interplay of the SCO and a PT in the pure 100P.

\section{Results}

\section{SCO properties of 100As}

The magnetic behaviour of 100As, recorded at $1 \mathrm{~K} \mathrm{~min} \mathrm{~m}^{-1}$ between 10 and $300 \mathrm{~K}$, is shown in Fig. $1 \mathrm{a}$ in the form of $\chi_{\mathrm{M}} T v s$.

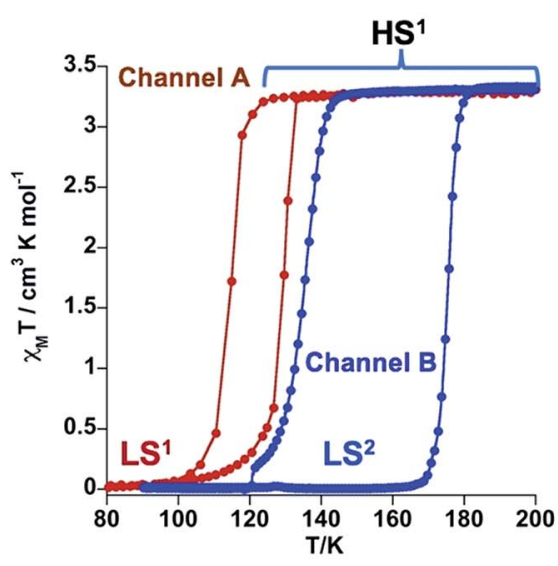

\begin{tabular}{ll}
\hline \% of As, $\mathbf{x}=\mathbf{0}$ & label \\
\hline $0 \%$ & $\mathbf{1 0 0 P}=\mathbf{0 0 A s}$ \\
$12 \%$ & $\mathbf{1 2 A s}$ \\
$22 \%$ & $\mathbf{2 2 A s}$ \\
$38 \%$ & $\mathbf{3 8 A s}$ \\
$46 \%$ & $\mathbf{4 6 A s}$ \\
$56 \%$ & $\mathbf{5 6 A s}$ \\
$63 \%$ & $\mathbf{6 3 A s}$ \\
$71 \%$ & $\mathbf{7 1 A s}$ \\
$86 \%$ & $\mathbf{8 6 A s}$ \\
$100 \%$ & $\mathbf{1 0 0 A s}$ \\
& \\
\hline \% of $\mathbf{M}^{\mathrm{II}}, \mathbf{y}=\mathbf{0}$ & \\
\hline $21 \%, \mathrm{Zn}$ & $\mathbf{2 1 Z n}$ \\
$17 \%, \mathrm{Ni}$ & $\mathbf{1 7 N i}$ \\
$100 \%, \mathrm{Ni}$ & $\mathbf{1 0 0 N i}$ \\
\hline
\end{tabular}

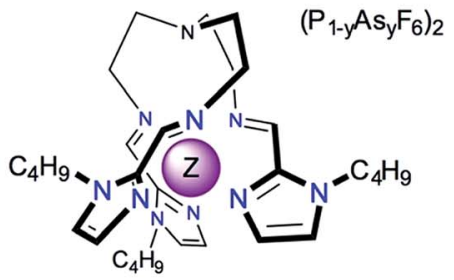

$\mathrm{Z}=\mathrm{Fe}_{1-\mathrm{x}} \mathrm{M}_{\mathrm{x}}$

Scheme 1 Description of the SCO behavior of 100P. $\left[\mathrm{Fe}_{1-x} \mathrm{M}_{x}(n \mathrm{Bu} \text {-im) })_{3}(\right.$ tren $\left.)\right]\left(\mathrm{P}_{1-y} \mathrm{As}_{y} \mathrm{~F}_{6}\right)_{2}$ system $(\mathrm{M}=\mathrm{Ni}, \mathrm{Zn})$. 
(a)
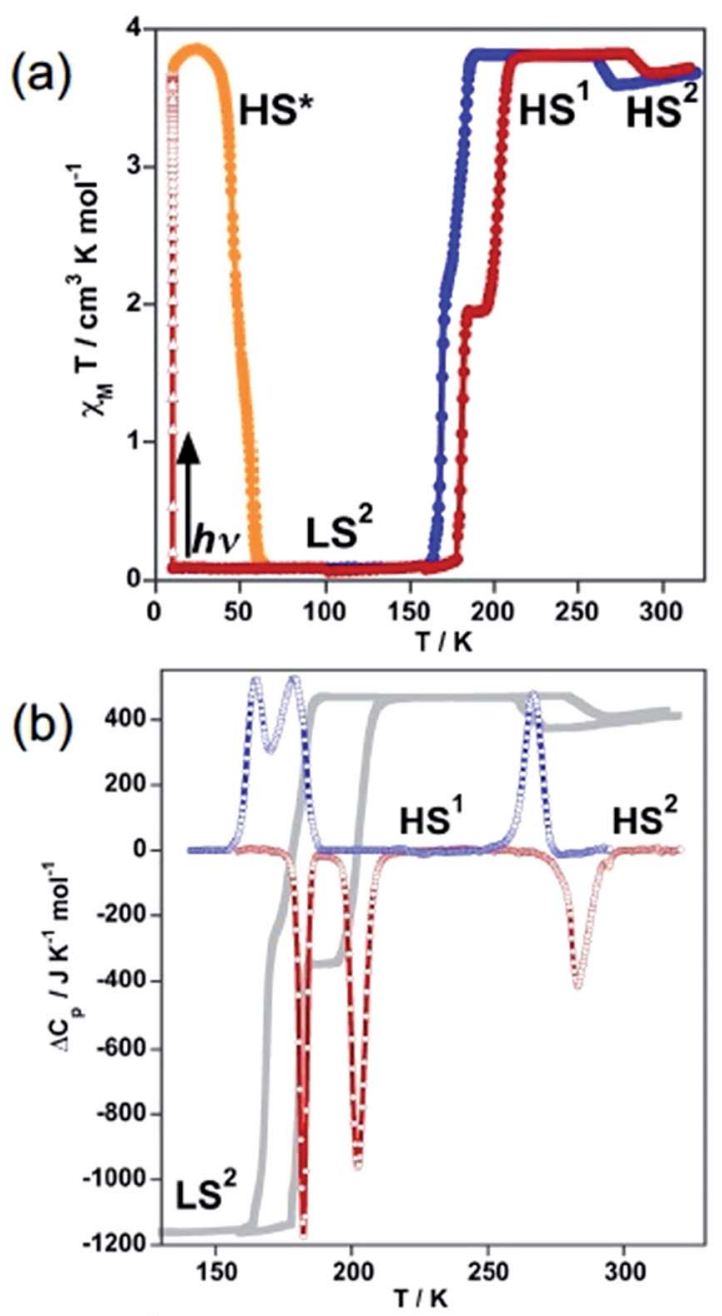

(c)

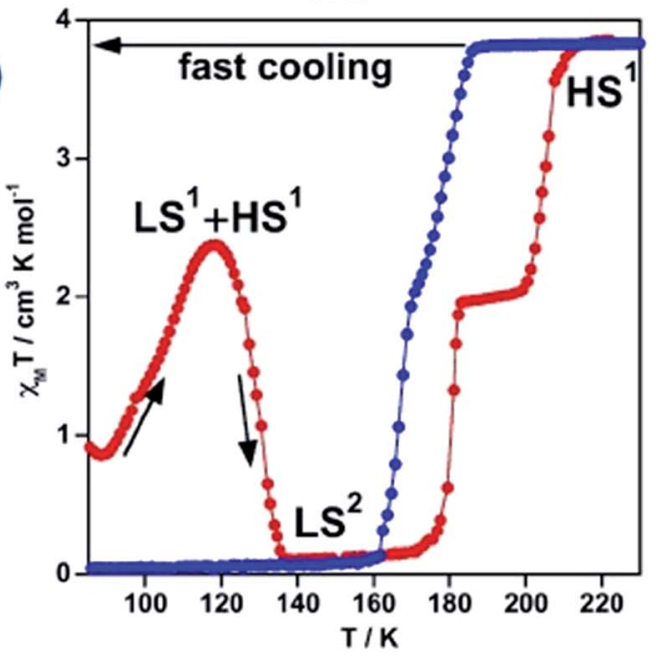

Fig. 1 Spin crossover behaviour of 100As: (a) magnetic and photomagnetic properties; (b) differential scanning calorimetry (DSC); and (c) quenching of the HS state. Blue and red filled circles correspond to the cooling and heating modes, respectively. Gray lines correspond to the heat flow measured by DSC.

$T\left(\chi_{\mathrm{M}}\right.$ is the molar magnetic susceptibility and $T$ is the temperature). At $300 \mathrm{~K}$, the $\chi_{\mathrm{M}} T$ value is close to $3.68 \mathrm{~cm}^{3} \mathrm{~K}$ $\mathrm{mol}^{-1}$ as expected for an $\mathrm{Fe}^{\mathrm{II}}$ compound in the HS state $(S=2)$.
On cooling a gradual decrease of the $\chi_{\mathrm{M}} T$ value down to 3.56 $\mathrm{cm}^{3} \mathrm{~K} \mathrm{~mol}^{-1}$ is followed by a limited but abrupt jump up to 3.80 $\mathrm{cm}^{3} \mathrm{~K} \mathrm{~mol}^{-1}$. This bistable behaviour is associated with a reversible crystallographic PT within the HS phase [HS ${ }^{1} \leftrightarrow$ $\left.\mathrm{HS}^{2}\right]$ (vide infra).

The shaped hysteresis is centred at $T_{\mathrm{c}}^{\mathrm{PT}}=276 \mathrm{~K}$ with the loop width $\Delta T_{\mathrm{c}}^{\mathrm{PT}}=17 \mathrm{~K}$. Further cooling does not reveal any marked evolution of $\chi_{\mathrm{M}} T$ down to $188 \mathrm{~K}$, where an abrupt twostep decrease down to zero value is detected $(S=0)$ with a welldefined plateau of the ascending curve at $50 \%$ conversion upon subsequent heating. The two steps centred at $T_{\mathrm{c}}^{1}=175 \mathrm{~K}$ and $T_{\mathrm{c}}^{2}=193 \mathrm{~K}$ are characterised by a hysteresis loop $\Delta T_{\mathrm{c}}^{1}=14$ $\mathrm{K}$ and $\Delta T_{\mathrm{c}}^{2}=23 \mathrm{~K}$ wide, respectively. In opposite to $100 \mathrm{P}$, no remarkable kinetic effects were observed for the range of temperature-sweeping rates $4-0.5 \mathrm{~K} \mathrm{~min}^{-1}$ in the magnetic response of 100As (Fig. S1†). However, when cooling from 300 $\mathrm{K}$ to $80 \mathrm{~K}$ in $c a .15 \mathrm{~s}\left(\approx 900 \mathrm{~K} \mathrm{~min}^{-1}\right)$ partial thermal trapping of the sample was observed (Fig. 1c). At $80 \mathrm{~K}$ the $\chi_{\mathrm{M}} T$ value of the trapped sample is $c a .1 \mathrm{~cm}^{3} \mathrm{~K} \mathrm{~mol}^{-1}$ and upon heating at $0.3 \mathrm{~K} \mathrm{~min}^{-1}$ it increases to reach a maximum value of $2.37 \mathrm{~cm}^{3}$ $\mathrm{K} \mathrm{mol}^{-1}$ at $120 \mathrm{~K}$, which corresponds to $c a .62 \%$ of the $\mathrm{Fe}^{\mathrm{II}}$ centres in the HS state. Then, at higher temperatures the compound relaxes back to the LS state and upon further heating it reaches the HS state. As a hypothesis and by similarity with 100P the trapped state could be a mixture of the states $\mathrm{LS}^{1}$ and $\mathrm{HS}^{1}$ and the LS state attained after relaxation should correspond to the $\mathrm{LS}^{2}$ phase (vide infra).

Quantitative photo-generation of the metastable HS* state at low temperature, the so-called light induced excited spin state trapping (LIESST) experiment, ${ }^{13}$ was carried out at $10 \mathrm{~K}$ by irradiating a microcrystalline sample $(0.75 \mathrm{mg})$ of $100 \mathrm{As}$ with red light $(\lambda=633 \mathrm{~nm})$ for over $3 \mathrm{~h}$. Further heating of the sample in the photo-stationary HS* state in the dark at 0.3 $\mathrm{K} \mathrm{min}^{-1}$ uncovers a two-step LIESST relaxation process with $T_{\text {LIESST1 }}=45 \mathrm{~K}$ and $T_{\text {LIESST2 }}=57 \mathrm{~K}$ (Fig. $1 \mathrm{a}$ ) relevant to the twostep thermal SCO.

Differential scanning calorimetry (DSC) measurements were carried out for 100As in the cooling and heating modes to support the magnetic bistability data and quantify the thermodynamic parameters associated with the SCO and PT. The corresponding anomalous variation of the heat capacity $\Delta C_{\mathrm{p}}$ vs. $T$ plots is depicted in Fig. $1 \mathrm{~b}$ overlaid with the magnetic data. Upon cooling/heating three processes are detected at critical temperatures $T_{\mathrm{c}}^{1}=174 \mathrm{~K}\left(\Delta T_{\mathrm{c}}^{1}=17 \mathrm{~K}\right), T_{\mathrm{c}}^{2}=191 \mathrm{~K}$ $\left(\Delta T_{\mathrm{c}}^{2}=23 \mathrm{~K}\right)$ and $T_{\mathrm{c}}^{\mathrm{PT}}=275 \mathrm{~K}\left(\Delta T_{\mathrm{c}}^{\mathrm{PT}}=16 \mathrm{~K}\right)$ confirming the reversibility of the two-step SCO process and of the PT. The enthalpy and entropy changes of the PT averaged over both runs, $\Delta H^{\mathrm{PT}}=3.94 \mathrm{~kJ} \mathrm{~mol}^{-1}$ and $\Delta S^{\mathrm{PT}}=14.29 \mathrm{~J} \mathrm{~K}^{-1} \mathrm{~mol}^{-1}$, account for the substantial rearrangements associated with order/disorder events of the butyl groups and the anions (vide infra). The averaged enthalpy and entropy for the two low temperature peaks, $\Delta H_{\mathrm{SCO}}=10.3 \mathrm{~kJ} \mathrm{~mol}^{-1}$ and $\Delta S_{\mathrm{SCO}}=59.5 \mathrm{~J}$ $\mathrm{K}^{-1} \mathrm{~mol}^{-1}$, respectively, exceed values reported for each of the two transitions LS $\leftrightarrow$ HS in 100P $\left[\Delta H_{\mathrm{SCO}}\left(\mathrm{LS}^{1} \leftrightarrow \mathrm{HS}^{1}\right)=\right.$ $5.2 \mathrm{~kJ} \mathrm{~mol}^{-1}$ and $\Delta S_{\mathrm{SCO}}\left(\mathrm{LS}^{1} \leftrightarrow \mathrm{HS}^{1}\right)=41.6 \mathrm{~J} \mathrm{~K}^{-1} \mathrm{~mol}^{-1}$; $\Delta H_{\mathrm{SCO}}\left(\mathrm{LS}^{2} \leftrightarrow \mathrm{HS}^{1}\right)=6.8 \mathrm{~kJ} \mathrm{~mol}^{-1}$ and $\Delta \mathrm{S}_{\mathrm{SCO}}\left(\mathrm{LS}^{2} \leftrightarrow \mathrm{HS}^{1}\right)=$ $\left.39.5 \mathrm{~J} \mathrm{~K}^{-1} \mathrm{~mol}^{-1}\right] .{ }^{11 b}$ 


\section{SCO properties of 100P under pressure}

The SCO properties of 100P (channel A and channel B) and 100As differ in critical temperatures, hysteresis width and more notably in nature (one or two step). The observed $30 \mathrm{~K}$ upward shift of the average critical temperature when replacing $\mathrm{PF}_{6}{ }^{-}$ with $\mathrm{AsF}_{6}{ }^{-}$suggests the introduction of additional chemical pressure in 100As as a result of the slightly larger ionic radius of As. To support this hypothesis, we have investigated the effect of small applied hydrostatic pressure on the SCO behaviour of 100P. At ambient pressure, in the cooling mode $\left(1 \mathrm{~K} \mathrm{~min}^{-1}\right)$, 100P displays essentially the behaviour of channel A. At a pressure of $0.11 \mathrm{GPa}$ the SCO shifts upwards by $100 \mathrm{~K}$, and, surprisingly, it becomes two-step with critical temperatures centred at $T_{\mathrm{c}}^{1}=221 \mathrm{~K}$ and $T_{\mathrm{c}}^{2}=251 \mathrm{~K}$, characterised by a hysteresis loop $\Delta T_{\mathrm{c}}^{1}=13 \mathrm{~K}$ and $\Delta T_{\mathrm{c}}^{2}=39 \mathrm{~K}$, respectively, and a well-defined intermediate plateau on heating as shown in Fig. 2. This SCO is practically that of 100As at ambient pressure. Increasing pressure up to $0.14 \mathrm{GPa}$ shifts the transition to higher temperatures $\left(T_{\mathrm{c}}^{1}=245 \mathrm{~K}, \Delta T_{\mathrm{c}}^{1}=13 \mathrm{~K}\right.$ and $T_{\mathrm{c}}^{2}=285 \mathrm{~K}$, $\left.\Delta T_{\mathrm{c}}^{2}=36 \mathrm{~K}\right)$. Interestingly, these results demonstrate very similar effects on the SCO of the complex cation whatever the nature of the applied pressure, i.e. external or "internal" generated by $\mathrm{PF}_{6}{ }^{-} \leftrightarrow \mathrm{AsF}_{6}{ }^{-}$anion substitution. A second relevant finding is the hypersensitivity of $100 \mathrm{P}$ towards imposed external pressure with dependence $\mathrm{d}\left\langle T_{\mathrm{c}}\right\rangle / \mathrm{d} p \approx 1000 \mathrm{~K} / \mathrm{GPa}$, where $\left\langle T_{\mathrm{c}}\right\rangle=\left(T_{\mathrm{c} 1}+T_{\mathrm{c} 2}\right) / 2$, although the regularly observed value lies in the range of $150-200 \mathrm{~K} / \mathrm{GPa}$ (ref. 14) (Fig. S2 $\dagger$ ).

\section{Study of $\left[\mathrm{Fe}_{1-x} \mathbf{M}_{x}(n \mathrm{Bu} \text {-im })_{3}(\right.$ tren $\left.)\right]\left(\mathbf{P}_{1-y} \mathbf{A s}_{y} \mathbf{F}_{6}\right)_{2}$ molecular alloys}

The high sensitivity of the SCO properties of 100P to external hydrostatic pressure, also apparent when internal "chemical pressure" increases when replacing $\mathrm{PF}_{6}{ }^{-}$with $\mathrm{AsF}_{6}{ }^{-}$, prompted us to study solid solutions based on anion $\left(\mathrm{PF}_{6}{ }^{-} \rightarrow \mathrm{AsF}_{6}{ }^{-}\right)$ and metal $\left(\mathrm{Fe}^{\mathrm{II}} \rightarrow \mathrm{M}^{\mathrm{II}}\right)$ substitution. A series of solid solutions were prepared in the same way as $100 \mathrm{P}$ and 100As but containing mixtures of $\mathrm{PF}_{6}{ }^{-}$and $\mathrm{AsF}_{6}{ }^{-}$anions in a calculated

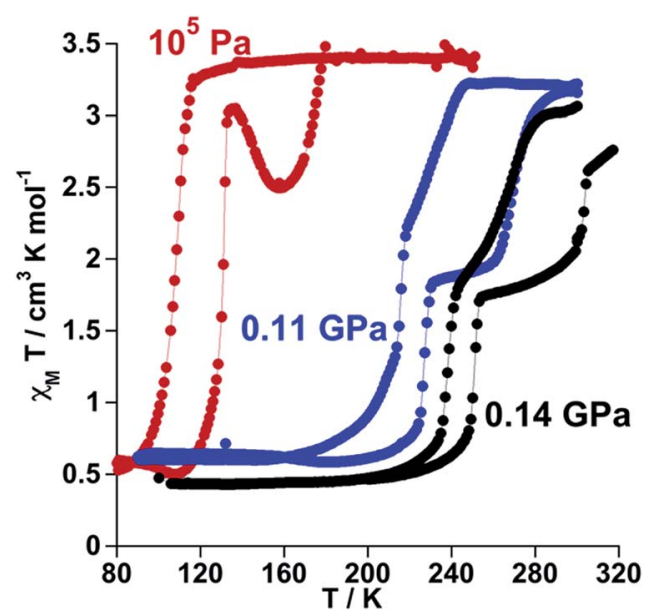

Fig. 2 Temperature dependence of $\chi_{M} T$ vs. $T$ for $100 P$ at different pressure values. ratio. It was found that the PXRD profiles of 22As-56As, as well as of $21 \mathrm{Zn}$ and $17 \mathrm{Ni}$, are indistinguishable from that of $100 \mathrm{P}$ (Fig. 3). On the other hand, for 71As, a shift/coalescence of diffraction peaks is observed in the high angle range, in addition to the change of peak intensity, although in the low angle range the diffraction patterns perfectly match that of 100P. These findings are consistent with the evolution of the magnetic properties on isostructural substitution in the aforementioned series.

Gradual substitution of $\mathrm{PF}_{6}{ }^{-}$with $\mathrm{AsF}_{6}{ }^{-}$anions continuously reshapes the original SCO behaviour of 100P stabilizing a phase which compares well with channel B. This is illustrated in Fig. $4 \mathrm{~b}-\mathrm{g}$ where the SCO of pristine $100 \mathrm{P}$, recorded at scan rate $2 \mathrm{~K} \mathrm{~min}^{-1}$, is also included for comparison (grey line). For 22As, channel A is prevailing and a low temperature hysteresis is still observed but an increase of the relaxation rate favouring channel $\mathrm{B}$ is obvious (Fig. 4b). Increasing the concentration of $\mathrm{AsF}_{6}{ }^{-}$in 29As, 38As, 46As and 56As progressively accelerates relaxation and suppresses channel A in favour of channel B, which finally in 71As produces a singlestep hysteresis loop centred at $T_{\mathrm{c}}=171 \mathrm{~K}$ with $\Delta T_{\mathrm{c}}=34 \mathrm{~K}$. Further increase of $\mathrm{AsF}_{6}{ }^{-}$affords compound 86As that gives rise to a narrow two-step SCO similar to that of the pristine 100As (Fig. S3†). It is worth mentioning that the PT within the HS phase $\mathrm{HS}^{1} \leftrightarrow \mathrm{HS}^{2}$ increases in amplitude and decreases in temperature as the amount of $\mathrm{AsF}_{6}{ }^{-}$increases in the molecular alloy (see Fig. $\mathrm{S} 4 \dagger$ ).

Interestingly, stabilization of channel A is achieved by partial substitution above a certain threshold value of $\mathrm{Fe}^{\mathrm{II}}$ with $\mathrm{Zn}^{\mathrm{II}}$ or $\mathrm{Ni}^{\mathrm{II}}$, i.e. $y \geq 0.21$ for $\mathrm{Zn}^{\mathrm{II}}$ or $y \geq 0.17$ for $\mathrm{Ni}^{\mathrm{II}}$. The resulting isostructural solid solutions $21 \mathrm{Zn}$ or $17 \mathrm{Ni}$ display one step cooperative SCO with critical temperatures centred at $T_{\mathrm{c}}=117$ and $121 \mathrm{~K}$, characterized by $\Delta T_{\mathrm{c}}=7$ and $3 \mathrm{~K}$ wide hysteresis loops, respectively, at any rate down to $0.5 \mathrm{~K} \mathrm{~min}^{-1}$ (Fig. $4 \mathrm{~h}$, for $17 \mathrm{Ni}$ see also Fig. S5 $\dagger$ ). The pure compound $100 \mathrm{Ni}$ shows a constant susceptibility value of $\chi_{\mathrm{M}} T \approx 1.2 \mathrm{~cm}^{3} \mathrm{~K} \mathrm{~mol}^{-1}$ in the

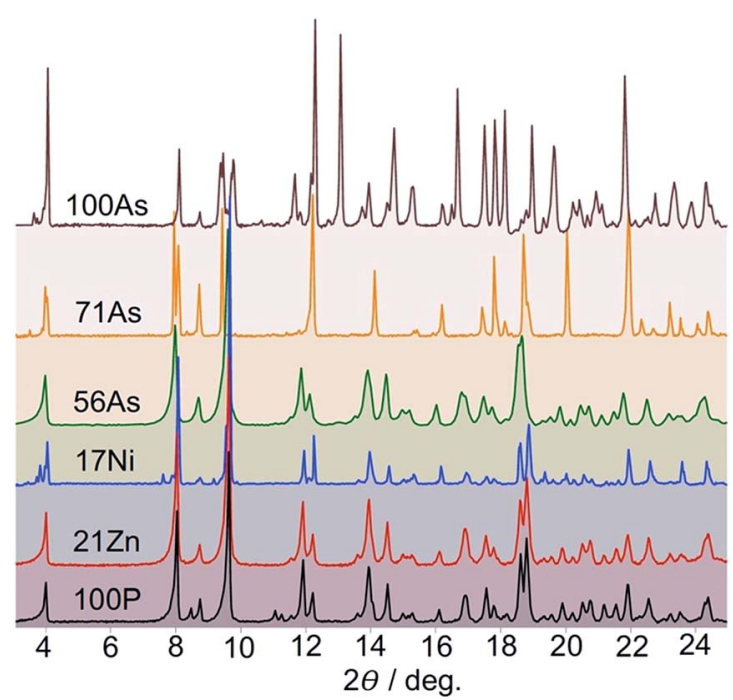

Fig. 3 X-ray powder diffraction patterns of indicated diluted compounds at RT. 

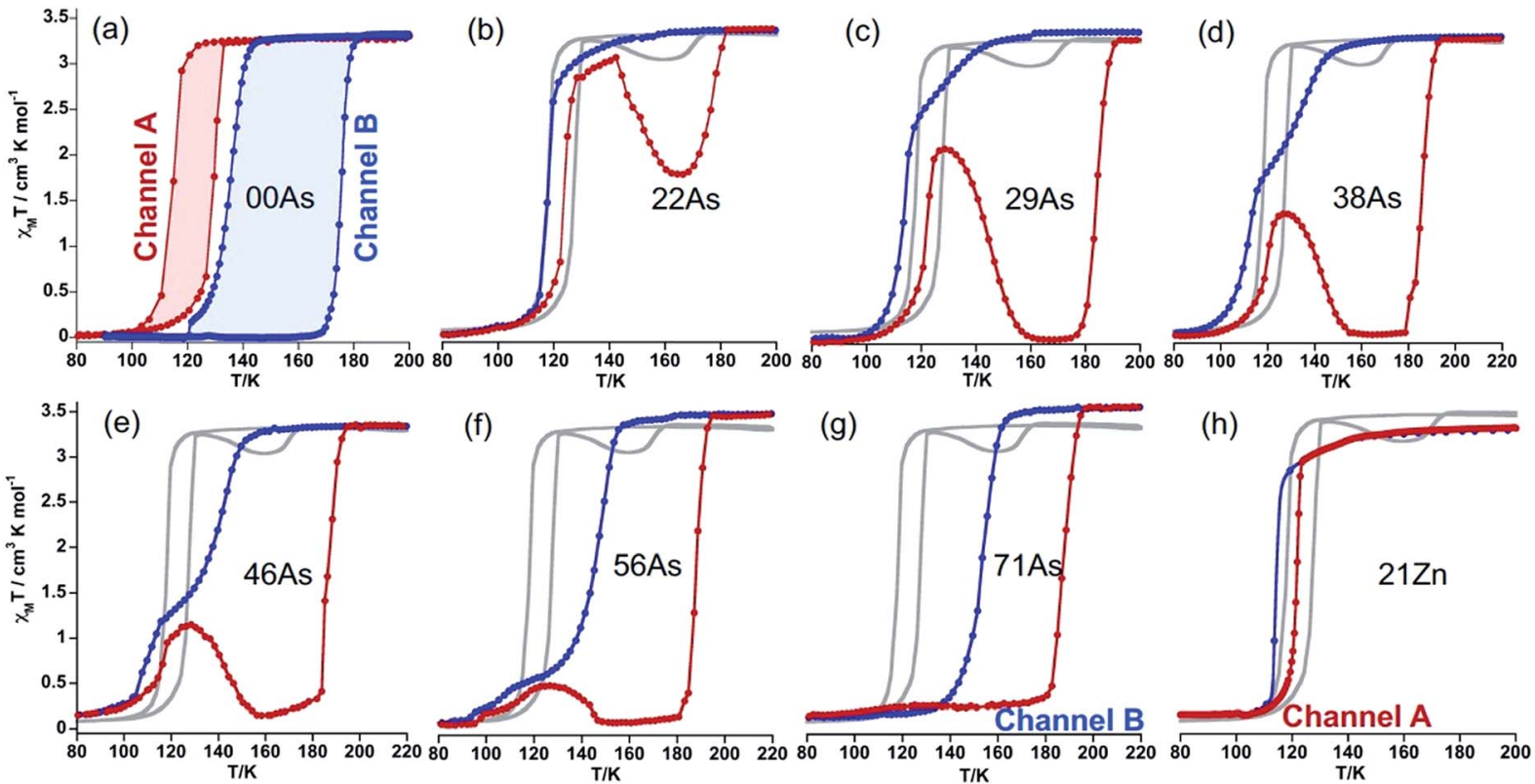

Fig. 4 (a) SCO behaviour of 100P, (red and blue curves measured at $4 \mathrm{~K} \mathrm{~min}^{-1}$ and $0.25 \mathrm{~K} \mathrm{~min}^{-1}$, respectively). (b-f) Influence of successive replacement of $\mathrm{PF}_{6}{ }^{-}$with $\mathrm{AsF}_{6}{ }^{-}$on the $\mathrm{SCO}$ properties. The red curve corresponds to heating, blue curve to cooling, and grey curve to the SCO of $100 \mathrm{P}$ measured at $2 \mathrm{~K} \mathrm{~min}^{-1}$. ( $\mathrm{g}$ and $\mathrm{h}$ ) Effective separation of the two channels.

temperature range $50-300 \mathrm{~K}$ without any irregularities (Fig. S6†).

It is worth noting that despite the clear kinetic stabilization of channel B for 71As, thermal quenching allows trapping the sample into the hidden channel A. For example, after cooling 71 As from $300 \mathrm{~K}$ to 80 at $c a .800 \mathrm{~K} \mathrm{~min}^{-1}$ the $\chi_{\mathrm{M}} T$ value is essentially that of the $\mathrm{Fe}^{\mathrm{II}}$ in the LS state $\left(0.22 \mathrm{~cm}^{3} \mathrm{~K} \mathrm{~mol}^{-1}\right)$ (see Fig. 5). Then, when heating at $0.3 \mathrm{~K} \mathrm{~min}^{-1}, \chi_{\mathrm{M}} T$ increases to attain a value of $3.20 \mathrm{~cm}^{3} \mathrm{~K} \mathrm{~mol}^{-1}$ at $127 \mathrm{~K}$, indicating that the compound is essentially HS. Upon further heating the system first relaxes back to a LS phase and later attains the thermodynamically stable HS state.

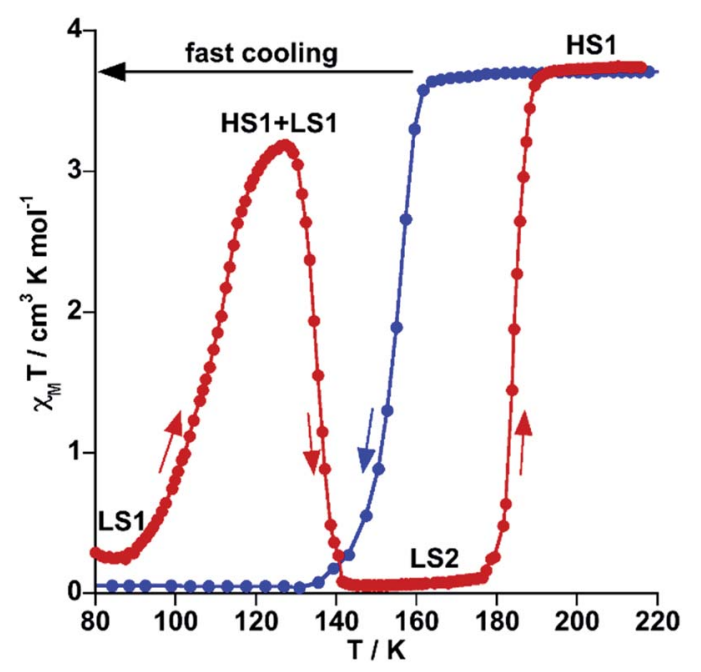

Fig. 5 Thermal quenching of the HS state for 71 As. Blue and red filled circles correspond to the cooling and heating modes, respectively.

\section{Structural analysis}

Structure of 100As. Compound 100As is essentially a structural analogue of 100P. Based on the magnetic behaviour (see Fig. 1a and b), the crystal structure of 100As was investigated at $120 \mathrm{~K}, 230 \mathrm{~K}$ and $300 \mathrm{~K}$ where, respectively, the $\mathrm{LS}^{2}, \mathrm{HS}^{1}$ and $\mathrm{HS}^{2}$ phases are stable. The transformation between these three phases involves two consecutive crystallographic PTs associated with important structural reorganisation, which involves remarkable volume change without symmetry changes (space group $P \overline{1}$, Table $\mathrm{S} 1 \dagger$ ). However, after many attempts, it was impossible to achieve a full structural analysis of the $\mathrm{LS}^{2}$ phase because single crystals shatter during the $\mathrm{HS}^{1} \rightarrow \mathrm{LS}^{2}$ transformation. The same reason prevented us from structurally characterising the plateau centred at $190 \mathrm{~K}$ in the heating branch of the $\mathrm{LS}^{2} \rightarrow \mathrm{HS}^{1}$ transition. The unit cell consists of two crystallographically identical complex cations of opposite chirality and four $\mathrm{AsF}_{6}{ }^{-}$counterions (two crystallographically distinct sites, denoted as As1 and As2) balancing the charge. The $\mathrm{Fe}^{\mathrm{II}}$ ion is wrapped by three $n$-butyl- $1 H$-imidazol-2-ylimino moieties, defining a pseudo-octahedral $\left[\mathrm{FeN}_{6}\right]$ coordination environment (Fig. 6a), with Fe-N average bond lengths typical for the HS state and does not change substantially due to the PT: 2.199(4) $\AA$ and 2.190(7) $\AA$ at $230 \mathrm{~K}\left(\mathrm{HS}^{1}\right)$ and $300 \mathrm{~K}\left(\mathrm{HS}^{2}\right)$, respectively (Fig. 6b, Table $\mathrm{S} 2 \dagger$ ).

Upside-down arranged complex molecules are self-organized in bilayer assemblies extending in the $a b$ plane whereas the $\mathrm{AsF}_{6}{ }^{-}$anions occupy both surfaces and the inner space of the bilayer (Fig. 7). At $230 \mathrm{~K}$ ( $\mathrm{HS}^{1}$ phase), the inner space anions $\left(\mathrm{As}_{1} \mathrm{~F}_{6}{ }^{-}\right)$are substantially shifted from the centre whereas the axes of anions are inclined with respect to the layer plane; the anions are ordered as well as butyl substituents of the complex cations, arrangement 1 in Fig. 7. On passing the temperature of the PT, the 

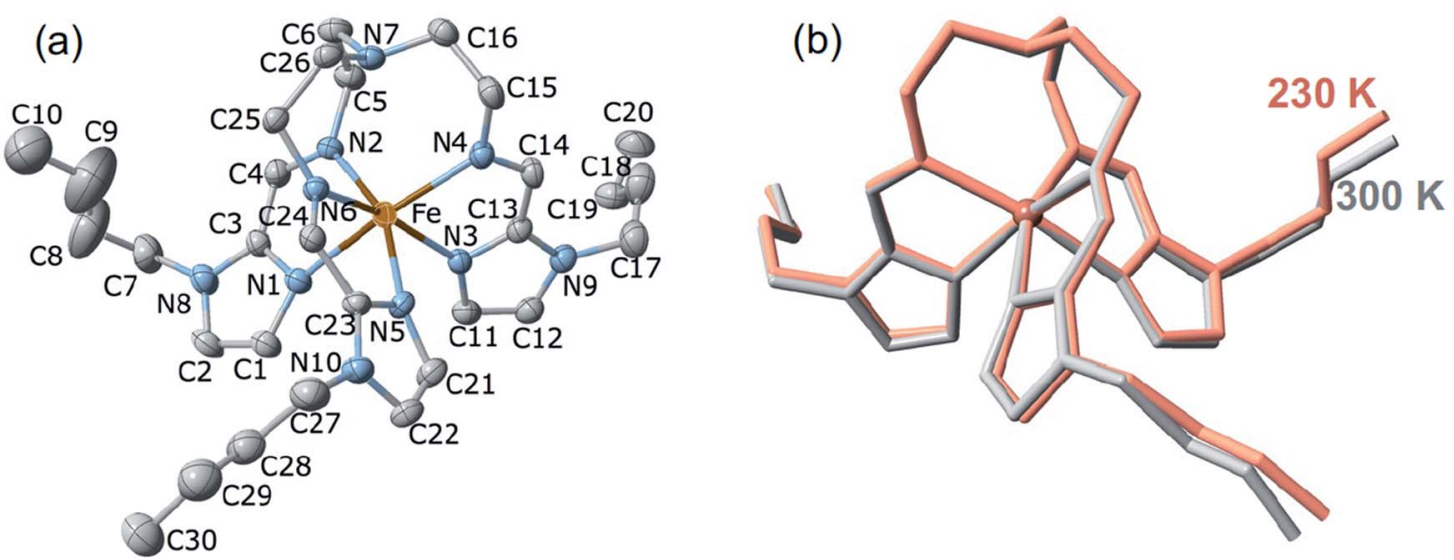

Fig. 6 (a) Projection of the cation of 100 As with the atom numbering scheme at $230 \mathrm{~K}$. Displacement ellipsoids are shown at the $30 \%$ probability level. Hydrogen atoms are omitted for clarity. (b) Minimized overlay of the complex cation in the $\mathrm{HS}^{1}$ (red) and HS $\mathrm{HS}^{2}$ (grey) phases.

anisotropic change of the lattice decreases the lattice parameter $c$ by $0.44 \AA$ that is reflected by the shrinking of the interlayer distance from $22.01 \AA$ at $230 \mathrm{~K}$ down to $21.85 \AA$ at $300 \mathrm{~K}$. Furthermore, the PT promotes arrangement 2 ( $\mathrm{HS}^{2}$ phase), for which inner space anions $\mathrm{As}_{1} \mathrm{~F}_{6}{ }^{-}$are located closer to the centre of the interspace between layers with their axes almost perpendicular to the layer plane (Fig. 7). Substantial disorder of the anions and butyl groups suggests that increasing entropy of the system is the driving force of the PT. Clearly, the transition is not related to the $\mathrm{SCO}$ as the coordination sphere of the $\mathrm{Fe}^{\mathrm{II}}$ remains practically intact, although the rearranged anions and butyl groups change the pattern of intermolecular contacts $\mathrm{CH} \cdots \mathrm{F}$ in the lattice. For example, in the $\mathrm{HS}^{1}$ phase one discrete interaction $\mathrm{C} 24 \cdots \mathrm{F} 2$ (As1) $=3.087(4) \AA$ is below the van der Waals radii (3.17 $\AA){ }^{15}$ in contrast to the $\mathrm{HS}^{2}$ phase where no viable $\mathrm{C} \cdots \mathrm{F}$ contacts are operative. Furthermore, the percentage of weak intermolecular contacts $\mathrm{C} \cdots \mathrm{F}, \mathrm{N} \cdots \mathrm{H}$ and $\mathrm{C} \cdots \mathrm{H}$ substantially changes due to the PT too, see Table S4. $\dagger$ This lattice dynamics in close proximity to the metal centre seems to noticeably affect the ligand field strength/g-factor and produce detectable magnetic bistability. ${ }^{16}$

It is worth recalling that similar structural rearrangement was observed for 100P. For cooling rates higher than $0.5 \mathrm{~K} \mathrm{~min}^{-1}, 100 \mathrm{P}$ displays arrangement 1 in the LS state $\left(\mathrm{LS}^{1}\right.$ phase) through channel $\mathrm{A}$, while above $T_{\mathrm{c}}^{\mathrm{PT}} \approx 127 \mathrm{~K}$ it adopts arrangement 2 ( $\mathrm{LS}^{2}$ phase) from channel B. Finally, on further heating it recovers arrangement 1 once the system reaches the HS state (HS ${ }^{1}$ phase) just above $T_{\mathrm{c}}^{\uparrow}=176 \mathrm{~K}$ (Fig. 3). It deserves to be noted the increase of disorder in the alkyl chains when both compounds adopt arrangement 2 , see comparison of the colour mapped complex cation in pairs $\mathrm{LS}^{1}-\mathrm{LS}^{2}$ and $\mathrm{HS}^{1}-\mathrm{HS}^{2}$ in Fig. $\mathrm{S} 7, \dagger$ which is supposed to be the driving force of the observed PTs.

On cooling 100As, a second transition occurs as deduced from the magnetic data (Fig. 1a), however, the crystal rapidly

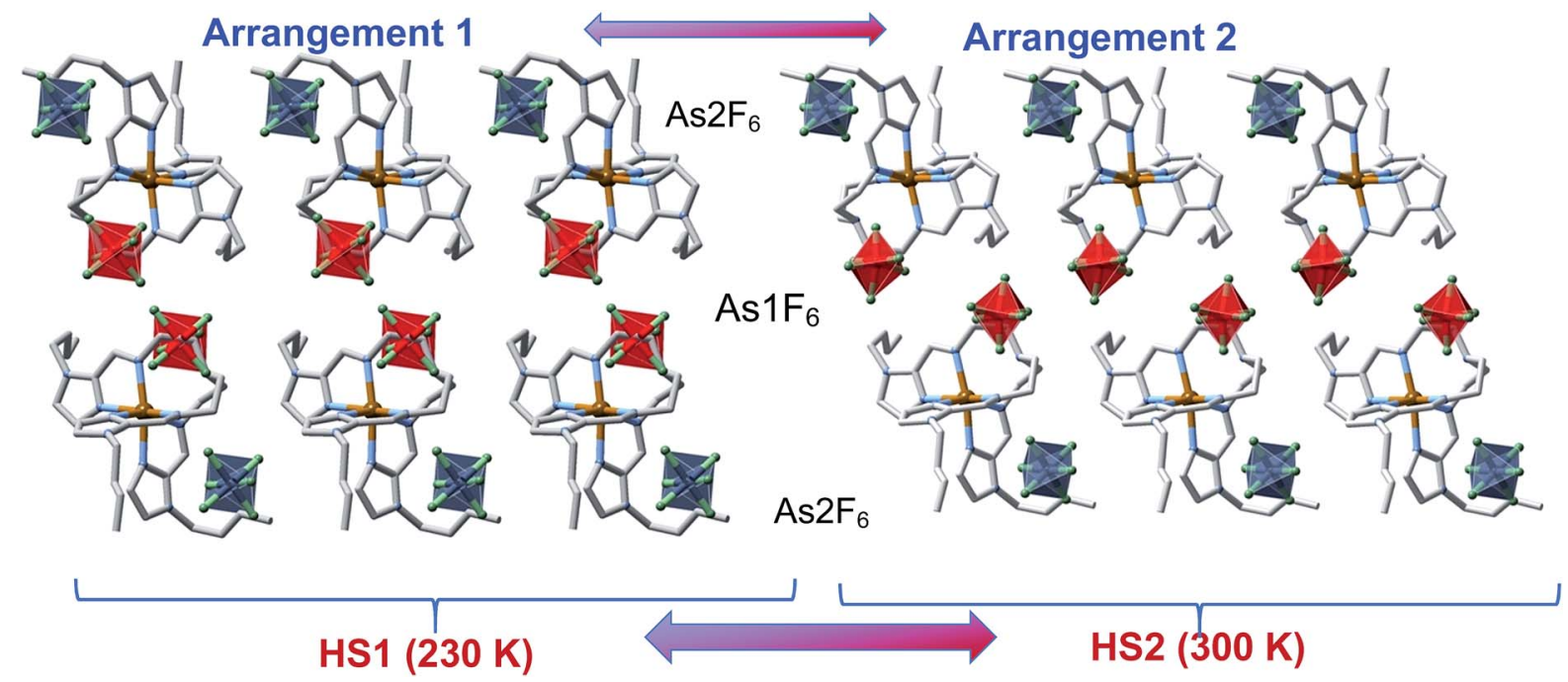

Fig. 7 Supramolecular bilayer organization of the complex molecules showing the location of the two crystallographically distinct AsF $_{6}{ }^{-} / \mathrm{PF}_{6}{ }^{-}$ anions [blue As $2 \mathrm{~F}_{6}{ }^{-} / \mathrm{P}_{2} \mathrm{~F}_{6}{ }^{-}$and red $\mathrm{As} \mathrm{F}_{6}{ }^{-} / \mathrm{P} \mathrm{F}_{6}{ }^{-}$octahedrons], illustrating arrangement 1 and arrangement 2. 
and irreversibly deteriorates due to the SCO and therefore it was impossible to collect crystallographic data of the $\mathrm{LS}^{2}$ phase at $120 \mathrm{~K}$ or of the intermediate plateau at $190 \mathrm{~K}$.

Structure of 71As and 100Ni. The impossibility of obtaining sufficient structural information about the nature of the LS state of 100As prompted us to try more robust single crystals from the $x \mathrm{AsF}_{6}{ }^{-}:(100-x) \mathrm{PF}_{6}{ }^{-}$solid solutions. It was expected to obtain direct information not only about the type of arrangement adopted by the LS state in this solid solution, which could be extrapolated to 100As, but also to obtain structural information about the HS state, in particular that of the metastable quenched $\mathrm{HS}^{1 \mathrm{q}}$ at $120 \mathrm{~K}$ (see Fig. 5). Indeed, robust single crystals of $71 \mathrm{AsF}_{6}{ }^{-}: 29 \mathrm{PF}_{6}{ }^{-}$(71As) appropriate for single crystal X-ray analysis were prepared. A single crystal of 71As was firstly measured at $230 \mathrm{~K}$ (see Tables S1 and S2 $\dagger$ ) where the structure presents, as expected, arrangement 1 and the $\mathrm{Fe}^{\mathrm{II}}$ centres are in the HS state (average Fe-N distance $=2.196 \AA$ ). The whole cation complex is virtually identical to that of $100 \mathrm{As}$ including the conformation of the butyl groups. Afterwards, the same crystal was slowly cooled from $230 \mathrm{~K}$ to $120 \mathrm{~K}$ to avoid any thermal quenching, and then the temperature was increased up to $157 \mathrm{~K}$ to place the system in the middle of the LS branch of the hysteresis and measured at this temperature (see Fig. 5). The corresponding structure exhibits arrangement 2 for the counterions with the butyl groups showing strong configurational differences with respect to the structure at $230 \mathrm{~K}$ (Fig. 8a). According to the magnetic properties, the $\mathrm{Fe}-\mathrm{N}$ average distance, $1.964 \AA$, shows the occurrence of a complete $\mathrm{HS}^{1} \rightarrow$ $\mathrm{LS}^{2}$ phase transformation (Table S2 $\dagger$ ).

Another single crystal of 71As was cooled directly from $300 \mathrm{~K}$ to $120 \mathrm{~K}$ and the structure of the $\mathrm{HS}^{1 \mathrm{q}}$ phase was analysed (see Tables S1 and S2 $\dagger$ ). Despite the crystals being rather robust, we observed their deterioration during the measurement process due to relaxation from the quenched $\mathrm{HS}^{1 \mathrm{q}}$ to the $\mathrm{LS}^{2}$ phase at $120 \mathrm{~K}$. Consequently, in order to get reasonably good crystal data, initial partial data collection for the resolution of the structure was recorded. Indeed, this relaxation was slow enough to allow the acquisition of the required data (stable for $c a .45$ min) to determine the structure before the collapse of the crystal. The analysis of the structure is consistent with the magnetic data and, based on the $\mathrm{Fe}-\mathrm{N}$ average bond length, only $c a .5 \%$ of the $\mathrm{Fe}^{\mathrm{II}}$ centres have relaxed to the $\mathrm{LS}^{2}$ state. The metastable quenched $\mathrm{HS}^{1 \mathrm{q}}$ retains arrangement 1 of the parent $\mathrm{HS}^{1}$ phase and the $\left[\mathrm{Fe}(n \mathrm{Bu}-\mathrm{im})_{3}(\text { tren })\right]^{2+}$ cation is essentially the same except for the butyl [Im-C7-C8-C9-C10] which adopts a divergent configuration (see Fig. 8b).

The crystal structure of $100 \mathrm{Ni}$, solved at $110 \mathrm{~K}$, closely resembles that of $100 \mathrm{P}$ in $\mathrm{LS}^{1}$ phase, ${ }^{11 b}$ i.e. shows arrangement 1 (Fig. S8, Tables S1 and S3†).

\section{Concluding remarks}

The underlying reason for the observed rich magnetic behaviour of the systems 100P and 100As lies in their ability to exhibit ordered arrangement 1 and less ordered arrangement 2 in addition to the SCO transition between the HS and LS spin states. Both systems exhibit SCO behaviour synchronized with a structural PT featuring very slow kinetics compared with that of the SCO. Playing with this kinetics, the bistability domains of both transitions can overlap in temperature or can occur separately so that $100 \mathrm{P}$ and $100 \mathrm{As}$ can potentially form phases $\mathrm{LS}^{1}, \mathrm{HS}^{1}$ and $\mathrm{LS}^{2}, \mathrm{HS}^{2}$ and display transitions between them. Indeed, for 100P the phase bistability is operative in a temperature region overlapping with the SCO bistability giving the transition $\mathrm{HS}^{1} \rightarrow \mathrm{LS}^{2}$. Additionally, a narrow temperature window exists where the transition $\mathrm{HS}^{1} \rightarrow \mathrm{LS}^{1}$ occurs without change of the lattice arrangement. Moreover, the transition LS $^{1}$ $\rightarrow \mathrm{LS}^{2}$ is operative without change of the spin state but with a change of the lattice arrangement. The experimental data show the possibility of such transitions also for 100As and, additionally, at higher temperature another structural rearrangement $\mathrm{HS}^{1} \rightarrow \mathrm{HS}^{2}$ occurs within the HS state.

Thus, both systems can exhibit "ordered" LS $^{1}$ and HS ${ }^{1}$ phases and "disordered" $\mathrm{LS}^{2}$ and $\mathrm{HS}^{2}$ phases. For 100As we observe all four phases, for $100 \mathrm{P}$ all except the $\mathrm{HS}^{2}$, which is shifted so much in temperature that it does not occur below the melting
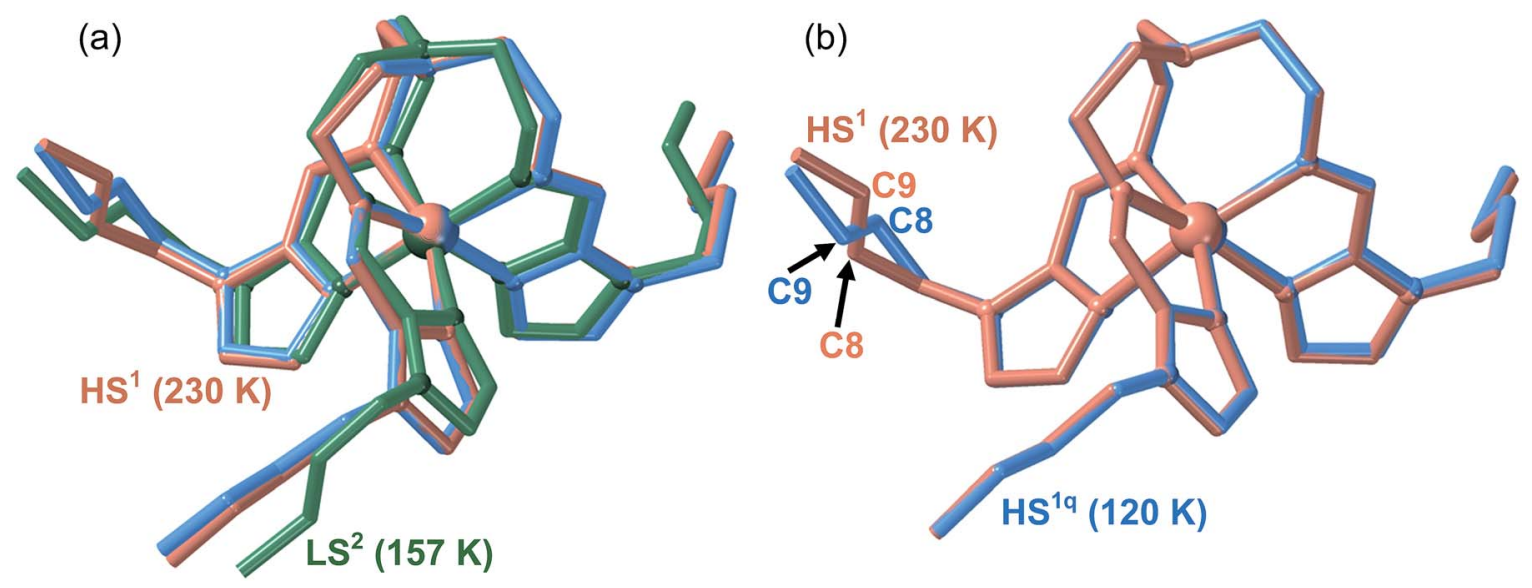

Fig. 8 Overlay of the complex cation in 71As: (a) combination of the $\mathrm{HS}^{1}$ (red, $230 \mathrm{~K}$ ) and $\mathrm{LS}^{2}$ (green, $157 \mathrm{~K}$ ) and HS $\mathrm{HS}^{1 \mathrm{a}}$ (blue, $120 \mathrm{~K}$ ) phases; (b) combination of the $\mathrm{HS}^{1}$ (red, $230 \mathrm{~K}$ ) and HS ${ }^{1 \mathrm{a}}$ (blue, $120 \mathrm{~K}$ ) phases showing the different configuration of the [Im-C7-C8-C9-C10] moiety. 
temperature of $100 \mathrm{P}$. The transition to the arrangement 2 phase occurs because the disordered $n$-butyl chains increase the entropy and decrease the Gibbs free energy of the system. The more prone tendency of 100As to disorder can be associated with the small volume expansion of the lattice induced by the $\mathrm{PF}_{6}{ }^{-} \rightarrow \mathrm{AsF}_{6}{ }^{-}$substitution and evidenced by the much faster kinetics featuring the $\mathrm{LS}^{2} \leftrightarrow \mathrm{HS}^{1}$ transition. The slightly larger $\mathrm{AsF}_{6}{ }^{-}$anions separate the SCO complex cations, thereby facilitating their $n$-butyl groups to become disordered and favoring the phases $\mathrm{LS}^{2}$ and $\mathrm{HS}^{2}$. This is corroborated by the transition $\mathrm{HS}^{1} \leftrightarrow \mathrm{HS}^{2}$ (not coupled with the SCO) and by the fact that this transition is not observed for 100P.

The shift of the SCO and phase bistabilities of the PT on passing from 100P to 100As might be rationalized considering the "chemical pressure" (CP) of the anions as a qualitative measure of average intermolecular interactions and electrostatic pressure in the lattices. Indeed, external pressure applied to $100 \mathrm{P}$ progressively shifts the $\mathrm{HS}^{1} \leftrightarrow \mathrm{LS}^{2}$ transition toward higher temperature and, more importantly, changes the hysteresis loop, which becomes two-step similarly to 100As. It is worth mentioning that the positive CP generated by application of "external" hydrostatic pressure increases the intermolecular contacts and stabilises the LS state by reducing the unit cell volume. In contrast, similar positive "internal" $\mathrm{CP}$ is generated upon $\mathrm{PF}_{6}{ }^{-} \rightarrow \mathrm{AsF}_{6}{ }^{-}$substitution, which involves an increase of the unit cell volume in $42.44 \AA^{3}$. To explain this apparent paradox we compared the crystal structures of 100P and 100As at the same temperature $(230 \mathrm{~K})$ making use of the Hirshfeld surface analysis. ${ }^{17}$ This analysis shows that the percentage of $\mathrm{C} \cdots \mathrm{F}$ contacts doubles when replacing $\mathrm{PF}_{6}{ }^{-}$with $\mathrm{AsF}_{6}{ }^{-}$(more moderate increase of contacts is also observed for $\mathrm{F} \cdots \mathrm{H}$ and $\mathrm{C} \cdots$ H) (Fig. S9, Table S4 $\dagger$ ). This can be rationalised from the estimated void space, 46.54 and $43.83 \AA^{3}$, available for $100 \mathrm{P}$ and 100As, respectively. ${ }^{17}$ Interestingly, the smaller empty space found for 100As shows that void space does not increase in parallel with the unit cell volume increase. This is the reason why the number of $\mathrm{F} \cdots \mathrm{C}$ contacts is larger for 100As, a fact in line with the observed increase of CP in 100As.

The similar chemical nature of both compounds makes them well suited for the study of the isomorphous series with varying ratio between the both. At a fixed scan rate of $2 \mathrm{~K} \mathrm{~min}^{-1}$ the kinetics of transitions $\mathrm{HS}^{1} \rightarrow \mathrm{LS}^{1}$ and $\mathrm{HS}^{1} \rightarrow \mathrm{LS}^{2}$ (memory channels $\mathrm{A}$ and $\mathrm{B}$, respectively) is dramatically affected by changing the $\mathrm{PF}_{6}{ }^{-}: \mathrm{AsF}_{6}{ }^{-}$ratio. This is reflected in the changing contribution of the two channels to the shape of the observed hysteresis loops. Progressively increasing the amount of $\mathrm{AsF}_{6}{ }^{-}$favours the SCO with structural rearrangement and makes the observation of the process $\mathrm{HS}^{1} \rightarrow \mathrm{LS}^{1}$ impossible on passing a threshold concentration. Thus, for 71As the coalescence of the two hysteretic spin transitions vanishes affording a rectangular well-shaped hysteresis loop, which corresponds to the transition $\mathrm{HS}^{1} \rightarrow \mathrm{LS}^{2}$ where the structural rearrangement is realized.

Opposite to the $\left[\mathrm{Fe}(n \mathrm{Bu}-\mathrm{im})_{3}(\right.$ tren $\left.)\right]\left(\mathrm{P}_{1-y} \mathrm{As}_{y} \mathrm{~F}_{6}\right)_{2}$ substituted systems, where included $\mathrm{AsF}_{6}{ }^{-}$anions create "positive" internal pressure and shift SCO upward in temperature, metal substitution in $\left[\mathrm{Fe}_{1-x} \mathrm{M}_{x}(n \mathrm{Bu}-\mathrm{im})_{3}(\right.$ tren $\left.)\right]\left(\mathrm{PF}_{6}\right)_{2}(21 \mathrm{Zn}$ or $17 \mathrm{Ni})$ can be considered as creating "negative" internal pressure, stabilizing low temperature SCO. Indeed, as follows from the experimental data, dilution with $\mathrm{Zn}^{\mathrm{II}}$ or $\mathrm{Ni}^{\mathrm{II}}$ ions, both more voluminous than the LS $\mathrm{Fe}^{\mathrm{II}}$ ion, predictably favours the SCO transition to the more voluminous $\mathrm{LS}^{1}$ phase and disfavours compact $\mathrm{LS}^{2}$ (cell volume 1994.7(5) and 1950.8(15) $\AA^{3}$, respectively) ${ }^{11 b}$ and makes the low temperature transition $\mathrm{LS}^{1} \leftrightarrow \mathrm{HS}^{1}$ the only option for the system. Thus, metal dilution with the $\mathrm{Ni}^{\mathrm{II}}$ or $\mathrm{Zn}^{\mathrm{II}}$ stabilizes the voluminous arrangement 1 in both spin states and effectively suppresses the transition to arrangement 2 .

In summary, we have reported an isomorphically substituted series of unusual $\mathrm{Fe}^{\mathrm{II}}$ SCO complexes displaying two memory channels. We found that metal substitution with $\mathrm{Ni}^{\mathrm{II}}$ or $\mathrm{Zn}^{\mathrm{II}}$ selectively favours arrangement 1 in both spin states, thus promoting a low temperature hysteretic SCO transition (channel A). On the other hand, substitution of its $\mathrm{PF}_{6}{ }^{-}$anion with $\mathrm{AsF}_{6}{ }^{-}$promotes a high temperature hysteretic SCO transition (channel B) as a result of favoured transformation to disordered arrangement 2 in the LS state, and thus the high temperature hysteretic transition is preferred.

For the first time, we demonstrate that decoupling of two synchronous cooperative events such as SCO and intrinsic structural phase transitions can be chemically achieved by choosing the appropriate isomorphous substitution (metal ion or anion in the present case) to selectively discriminate between two separate hysteretic SCO behaviours. The design of fully controllable smart materials able to respond to external stimuli in a desired way is a challenging target in materials science. The results here reported support the idea that bistable molecular materials exhibiting synergetic interplay between two or more phase transitions in the same crystal are particularly well suited to this end.

\section{Experimental}

\section{Materials}

Synthesis of precursors. All chemicals were purchased from commercial sources and used without further purification. 1Butyl-1H-imidazole-2-carbaldehyde and the complexes were synthesized according to the reported procedures. ${ }^{\mathbf{1 1 b}}$

$\left[\mathrm{Fe}(n \mathrm{Bu}-\mathrm{im})_{3} \mathrm{tren}\right]\left(\mathrm{AsF}_{6}\right)_{2} \quad(100 \mathrm{As})$. A filtered solution of $\mathrm{FeCl}_{2} \cdot 4 \mathrm{H}_{2} \mathrm{O}(0.043 \mathrm{~g}, 0.21 \mathrm{mmol})$ in absolute ethanol $(5 \mathrm{~mL})$ was added dropwise to a boiling solution of 1-butyl- $1 H$-imidazole-2carbaldehyde $(0.10 \mathrm{~g}, 0.65 \mathrm{mmol})$, tris(2-ethanolamine)amin (tren) $(0.031 \mathrm{~g}, 0.21 \mathrm{mmol})$ and [TBA] $\mathrm{AsF}_{6}(0.17 \mathrm{~g}, 0.43 \mathrm{mmol})$ in $5 \mathrm{~mL}$ of absolute ethanol. The resulting dark red-purple solution was stirred for $5 \mathrm{~min}$. After keeping the solution for several days at $25{ }^{\circ} \mathrm{C}$ in a thermostat bath, well-shaped redbrown crystals of the product were formed and isolated. Calcd for $\mathrm{C}_{30} \mathrm{H}_{48} \mathrm{As}_{2} \mathrm{~F}_{12} \mathrm{FeN}_{10}$ : C, 36.68; H, 5.01; N, 14.10. Found: C, 36.39; H, 5.35; N, 14.25 .

Synthesis of substituted compounds. The series $[\mathrm{Fe}(n \mathrm{Bu}-$ $\mathrm{im})_{3}($ tren $\left.)\right]\left(\mathrm{P}_{1-y} \mathrm{As}_{y} \mathrm{~F}_{6}\right)_{2}$ was synthesized in analogy to $100 \mathrm{P}$ and 100As by adding the appropriate mixture of [TBA] AsF $_{6}$ and [TBA] $\mathrm{PF}_{6}$ salts to the freshly prepared ethanolic solution of the complex cation $\left[\mathrm{Fe}(n \mathrm{Bu} \text {-im })_{3} \text { tren }\right]^{2+}$. Energy-dispersive X-ray spectroscopy (EDXS) was used to confirm the $\mathrm{P}$ and As 
stoichiometry of the formed crystals: $100 \mathrm{P}$ (100\% P, $0 \% \mathrm{As})$; 12As (88\% P, 12\% As); 22As (78\% P, 22\% As); 38As (62\% P, 38\% As); 46As (54\% P, 46\% As); 56As (44\% P, 56\% As); 63As (37\% P, $63 \%$ As); 71As (29\% P, 71\% As); 86As (14\% P, 86\% As); $100 \mathrm{As}$ ( $0 \% \mathrm{P}, 100 \%$ As). The successive replacement $\mathrm{PF}_{6}{ }^{-} \leftrightarrow \mathrm{AsF}_{6}{ }^{-}$was semi-quantitatively monitored following their characteristic IR modes: $\nu_{1}\left(\mathrm{PF}_{6}{ }^{-}\right)=839 \mathrm{~cm}^{-1}(\mathrm{vs}), \nu_{2}\left(\mathrm{PF}_{6}{ }^{-}\right)=557 \mathrm{~cm}^{-1}, \nu_{1}\left(\mathrm{AsF}_{6}{ }^{-}\right)$ $=700 \mathrm{~cm}^{-1}$ (vs) (see Fig. S10†).

Similarly, the solid solutions $\left[\mathrm{Fe}_{1-x} \mathrm{M}_{x}(n \mathrm{Bu} \text {-im })_{3}(\right.$ tren $\left.)\right]\left(\mathrm{PF}_{6}\right)_{2}$ $\left(\mathrm{M}=\mathrm{Zn}^{\mathrm{II}}, \mathrm{Ni}^{\mathrm{II}}\right)$ were confirmed via EDXS analysis: $17 \mathrm{Ni}(83 \% \mathrm{Fe}$, $17 \% \mathrm{Ni}$ ), 21Zn (79\% Fe, 21\% Zn).

\section{Physical characterization}

Magnetic measurements. Variable-temperature magnetic susceptibility data for bulk crystalline/microcrystalline samples $\left[\mathrm{Fe}_{1-x} \mathrm{M}_{x}(n \mathrm{Bu} \text {-im })_{3}(\right.$ tren $\left.)\right]\left(\mathrm{P}_{1-y} \mathrm{As}_{y} \mathrm{~F}_{6}\right)_{2}$ (ca. $\left.20 \mathrm{mg}\right)$ were recorded with a Quantum Design MPMS2 SQUID susceptometer equipped with a $7 \mathrm{~T}$ magnet, operating at $1 \mathrm{~T}$ and at temperatures $10-$ 400 K. Experimental susceptibilities were corrected for diamagnetism of the constituent atoms by the use of Pascal's constants. The LIESST experiments were performed at $10 \mathrm{~K}$ in a commercial sample holder (Quantum Design Fiber Optic Sample Holder), wherein a quartz bucket containing $0.75 \mathrm{mg}$ of microcrystals of 100As was held against the end of a quartz fiber coupled with a red laser $(633 \mathrm{~nm})$. The raw data were corrected for a background arising from the sample holder. The resulting magnetic signal was calibrated by scaling to match the obtained high temperature values with those of the bulk sample. Magnetic measurements under pressure were performed on $100 \mathrm{P}$ using a hydrostatic pressure cell made of hardened beryllium bronze with silicon oil as the pressure transmitting medium and operating over the pressure range $10^{5}$ to $10^{9} \mathrm{~Pa}^{18}$ The compound, $10 \mathrm{mg}$, was packed in a cylindrically shaped sample holder ( $1 \mathrm{~mm}$ in diameter and 5-7 $\mathrm{mm}$ in length) made up of very thin aluminum foil. The pressure was calibrated using the transition temperature of superconducting lead of high purity $99.999 \% .^{19}$

Calorimetric measurements. Differential scanning calorimetry measurements were performed using a Mettler Toledo DSC 821e calorimeter. Low temperatures were obtained with an aluminium block attached to the sample holder, refrigerated with a flow of liquid nitrogen and stabilized at a temperature of $110 \mathrm{~K}$. The sample holder was kept in a dry box under a flow of dry nitrogen gas to avoid water condensation. The measurements were carried out using around $12 \mathrm{mg}$ of microcrystalline 100As sealed in aluminium pans with a mechanical crimp. Temperature and heat flow calibrations were made with standard samples of indium by using its melting transition $(429.6 \mathrm{~K}$, $28.45 \mathrm{~J} \mathrm{~g}^{-1}$ ). An overall accuracy of $\pm 0.2 \mathrm{~K}$ in temperature and $\pm 2 \%$ in the heat capacity is estimated. The uncertainty increases for the determination of the anomalous enthalpy and entropy due to the subtraction of an unknown baseline.

Powder X-ray diffraction measurements (PXRD). PXRD measurements where performed on a PANalytical Empyrean Xray powder diffractometer (monochromatic $\mathrm{CuK} \alpha$ radiation).
Single crystal X-ray diffraction. Single-crystal X-ray data were collected with an Oxford diffraction supernova single crystal diffractometer using graphite monochromated $\mathrm{MoK}_{\alpha}$ radiation $(\lambda=0.71073 \AA)$. A multi-scan absorption correction was performed. The structures were solved by direct methods using SHELXS-2014 and refined by full-matrix least squares on $F^{2}$ using SHELXL-2014. ${ }^{20}$ Non-hydrogen atoms were refined anisotropically and hydrogen atoms were placed in calculated positions refined using idealized geometries (riding model) and assigned fixed isotropic displacement parameters. CCDC files CCDC 1879896-1879901 contain the supplementary crystallographic data for 100As (230 K), 100As (300 K), 71As (230 K), 71As $(120 \mathrm{~K}), 71 \mathrm{As}(157 \mathrm{~K}), 100 \mathrm{Ni}(110 \mathrm{~K})$, and CCDC 1892385 for 100P $(230 \mathrm{~K}) \cdot \dagger$

\section{Conflicts of interest}

There are no conflicts to declare.

\section{Acknowledgements}

This work was supported by the Spanish Ministerio de Economia y Competitividad (MINECO), FEDER (CTQ2016-78341-P), Unidad de Excelencia María de Maeztu (MDM-2015-0538), and the Generalitat Valenciana through PROMETEO/2016/147 and an EU Framework Program for Research and Innovation (RISE project number 734322). F. J. V. M. and M. M. S. thank MINECO for a predoctoral (FPI) grant.

\section{Notes and references}

1 (a) K. H. Bennemann, J. Phys.: Condens. Matter, 2011, 23, 073202; (b) O. Sato, Nat. Chem., 2016, 8, 644-656; (c) S.-y. Koshihara, J. Phys.: Conf. Ser., 2005, 21, 7-14.

2 (a) E. König, Struct. Bonding, 1991, 76, 51-152; (b) P. Gütlich, A. Hauser and H. Spiering, Angew. Chem., Int. Ed. Engl., 1994, 33, 2024-2054; (c) J. A. Real, A. B. Gaspar, V. Niel and M. C. Muñoz, Coord. Chem. Rev., 2003, 236, 121-141; (d) Spin Crossover in Transition Metal Compounds, ed. P. Gütlich and H. Goodwin, Top. Curr. Chem., 2004, vol. 233235; (e) J. A. Real, A. B. Gaspar and M. C. Muñoz, Dalton Trans., 2005, 2062-2079; (f) M. A. Halcrow, Polyhedron, 2007, 26, 3523-3576; (g) A. Bousseksou, G. Molnár, L. Salmon and W. Nicolazzi, Chem. Soc. Rev., 2011, 40, 3313-3335.

3 (a) O. Kahn and J. Martinez, Science, 1998, 279, 44-48; (b) M. Ohba, K. Yoneda, G. Agusí, M. C. Munoz, A. B. Gaspar, J. A. Real, M. Yamasaki, H. Ando, Y. Nakao, S. Sakaki and S. Kitagawa, Angew. Chem., Int. Ed., 2009, 48, 4767-4771; (c) L. Salmon, G. Molnar, D. Zitouni, C. Quintero, C. Bergaud, J.-C. Micheau and A. Bousseksou, J. Mater. Chem., 2010, 20, 5499-5503; (d) F. Prins, M. Monrabal-Capilla, E. A. Osorio, E. Coronado and H. S. J. van der Zant, Adv. Mater., 2011, 23, 1545-1549; (e) M. Matsuda, K. Kiyoshima, R. Uchida, N. Kinoshita and H. Tajima, Thin Solid Films, 2013, 531, 451-453; (f) H. J. Shepherd, I. y. A. Gural'skiy, 
C. M. Quintero, S. Tricard, L. Salmon, G. Molnár and A. Bousseksou, Nat. Commun., 2013, 4(1-9), 2607.

4 (a) H. Matsukizono, K. Kuroiwa and N. Kimizuka, Chem. Lett., 2008, 37, 446-447; (b) C. Lochenie, K. Schotz, F. Panzer, H. Kurz, B. Maier, F. Puchtler, S. Agarwal, A. Kohler and B. Weber, J. Am. Chem. Soc., 2018, 140, 700709; (c) T. Delgado, M. Meneses-Sánchez, L. Piñeiro-López, C. Bartual-Murgui, M. C. Muñoz and J. A. Real, Chem. Sci., 2018, 9, 8446-8452.

5 (a) Y.-C. Chen, Y. Meng, Z.-P. Ni and M.-L. Tong, J. Mater. Chem. C, 2015, 3, 945-949; (b) Y.-S. Koo and J. R. GalánMascarós, Adv. Mater., 2014, 26, 6785-6789.

6 S. Bonhommeau, P. G. Lacroix, D. Talaga, A. Bousseksou, M. Seredyuk, I. O. Fritsky and V. Rodriguez, J. Phys. Chem. $C, 2012,116,11251-11255$.

7 (a) G. Molnar, S. Rat, L. Salmon, W. Nicolazzi and A. Bousseksou, Adv. Mater., 2018, 30(1-23), 17003862; (b) K. Senthil Kumar and M. Ruben, Coord. Chem. Rev., 2017, 346, 176-205.

8 (a) T. Tayagaki, A. Galet, G. Molnar, M. C. Muñoz, A. Zwick, K. Tanaka, J. A. Real and A. Bousseksou, J. Phys. Chem. B, 2005, 109, 14859-14867; (b) C. Balde, C. Desplanches, P. Gutlich, E. Freysz and J. F. Letard, Inorg. Chim. Acta, 2008, 361, 3529-3533; (c) Z. Yu, T. Kuroda-Sowa, H. Kume, T. Okubo, M. Maekawa and M. Munakata, Bull. Chem. Soc. Jpn., 2009, 82, 333-337; (d) P. Chakraborty, C. Enachescu, A. Humair, L. Egger, T. Delgado, A. Tissot, L. Guenee, C. Besnard, R. Bronisz and A. Hauser, Dalton Trans., 2014, 43, 17786-17796; (e) C. Baldé, C. Desplanches, J. F. Létard and G. Chastanet, Polyhedron, 2017, 123, 138-144.

9 (a) C. A. Tovee, C. A. Kilner, J. A. Thomas and M. A. Halcrow, CrystEngComm, 2009, 11, 2069-2077; (b) M. A. Halcrow, Chem. Commun., 2010, 46, 4761-4763.

10 (a) D. Braga, G. Cojazzi, D. Paolucci and F. Grepioni, Chem. Commun., 2001, 803-804; (b) M. Zhao, H. Peng, J. Hu and Z. Han, Sens. Actuators, B, 2008, 129, 953-957; (c) R. Zhang, H. Jifan, H. Zhouxiang, Z. Ma, W. Zhanlei, Y. Zhang and Q. Hongwei, J. Rare Earths, 2010, 28, 591-595; (d) D. M. Pajerowski, T. Yamamoto and Y. Einaga, Inorg. Chem., 2012, 51, 3648-3655; (e) Y. Sun, Z. Zhu, J. Li, S. Gao, H. Xia, Z. You, Y. Wang and C. Tu, Opt. Mater., 2015, 49, 85-89; (f) S. Chorazy, J. J. Stanek, W. Nogaś, A. M. Majcher, M. Rams, M. Kozieł, E. Juszyńska-Gałązka, K. Nakabayashi, S.-i. Ohkoshi, B. Sieklucka and R. Podgajny, J. Am. Chem. Soc., 2016, 138, 1635-1646.

11 (a) M. Seredyuk, A. B. Gaspar, V. Ksenofontov, Y. Galyametdinov, J. Kusz and P. Gütlich, J. Am. Chem. Soc., 2008, 130, 1431-1439; (b) M. Seredyuk, M. C. Muñoz,
M. Castro, T. Romero-Morcillo, A. B. Gaspar and J. A. Real, Chem.-Eur. J., 2013, 19, 6591-6596; (c) M. Seredyuk, M. C. Muñoz, V. Ksenofontov, P. Gütlich, Y. Galyametdinov and J. A. Real, Inorg. Chem., 2014, 53, 8442-8454; (d) T. Romero-Morcillo, M. Seredyuk, M. C. Muñoz and J. A. Real, Angew. Chem., Int. Ed., 2015, 54, 14777-14781; (e) M. Seredyuk, K. Znovjyak, M. C. Munoz, Y. Galyametdinov, I. O. Fritsky and J. A. Real, RSC Adv., 2016, 6, 39627-39635; (f) T. Delgado, A. Tissot, L. Guénée, A. Hauser, F. J. Valverde-Muñoz, M. Seredyuk, J. A. Real, S. Pillet, E.-E. Bendeif and C. Besnard, J. Am. Chem. Soc., 2018, 140, 12870-12876.

12 (a) J. Jeftić, H. Romstedt and A. Hauser, J. Phys. Chem. Solids, 1996, 57, 1743-1750; (b) S. Hayami, Y. Komatsu, T. Shimizu, H. Kamihata and Y. H. Lee, Coord. Chem. Rev., 2011, 255, 1981-1990; (c) S. Schlamp, B. Weber, A. D. Naik and Y. Garcia, Chem. Commun., 2011, 47, 7152-7154; (d) M. Yamasaki and T. Ishida, J. Mater. Chem. C, 2015, 3, 7784-7787; (e) A. B. Gaspar and M. Seredyuk, Coord. Chem. Rev., 2014, 268, 41-58; (f) D. Rosario-Amorin, P. Dechambenoit, A. Bentaleb, M. Rouzières, C. Mathonière and R. Clérac, J. Am. Chem. Soc., 2018, 140, 98-101; $(g)$ T. Fujinami, K. Nishi, D. Hamada, K. Murakami, N. Matsumoto, S. Iijima, M. Kojima and Y. Sunatsuki, Inorg. Chem., 2015, 54, 7291-7300; (h) T. Ueno, Y. Ii, T. Fujinami, N. Matsumoto, S. Iijima and Y. Sunatsuki, Polyhedron, 2017, 136, 13-22; (i) M. Weselski, M. Książek, D. Rokosz, A. Dreczko, J. Kusz and R. Bronisz, Chem. Commun., 2018, 54, 3895-3898.

13 J. F. Létard, P. Guionneau, O. Nguyen, J. S. Costa, S. Marcen, G. Chastanet, M. Marchivie and L. Goux-Capes, Chem.-Eur. J., 2005, 11, 4582-4589.

14 V. Ksenofontov, A. B. Gaspar and P. Gütlich, Top. Curr. Chem., 2004, 235, 23-64.

15 A. Bondi, J. Phys. Chem., 1964, 68, 441-451.

16 G. Juhász, R. Matsuda, S. Kanegawa, K. Inoue, O. Sato and K. Yoshizawa, J. Am. Chem. Soc., 2009, 131, 4560-4561.

17 (a) M. J. Turner, J. J. Mckinnon, S. K. Wolff, D. J. Grimwood, P. R. Spackman, D. Jayatilaka and M. A. Spackman, CrystalExplorer 17.5, The University of Western Australia, 2018; (b) M. J. Turner, J. J. Mckinnon, D. Jayatilaka and P. R. Spackman, CrystEngComm, 2011, 13, 1804-1813.

18 M. Baran, V. P. Dyakonov, L. Gladczuk, G. G. Levchenko, S. Piechota and G. Szymczak, Phys. C, 1995, 241, 383-388.

19 A. Eiling and J. S. Schilling, J. Phys. F: Met. Phys., 1981, 11, 623-639.

20 G. M. Sheldrick, Acta Crystallogr., Sect. C: Struct. Chem., 2015, 71, 3-8. 